\title{
Research on the Influence of Sports Information Dissemination on Public Lifetime Sports Consciousness in the New Media Environment
}

\author{
Yanping Jiang \\ Xi`an Medical University, Xi`an, China \\ yanping@163.com
}

Keywords: Sports Information Dissemination, Public Lifetime Sports Consciousness, New Media Environment

\begin{abstract}
Sports media size and influence have made great progress in recent years. Combined with the characteristics of youth sports consciousness form, this paper analyzes the major media sports media in China, discusses the effect of the mass media sports consciousness and proposes sports media problems that should pay attention to.
\end{abstract}

\section{Introduction}

Currently, the mass media newspapers, magazines, television, Internet and other in social life increasingly plays an important role. The relationship between the media and the various aspects of society has become a hot sociological research, but research the relationship between the media and sports in the field of sports science is weak, in terms of breadth and depth are to be further strengthened. The mass media has a very important role in the formation of people's consciousness and values in sports, mass sports and cultural life is indispensable content. We discussed about the mass media on people's awareness of the impact of lifelong physical problems.

\section{The Status of China Sports Media}

TV media in terms of speed of information dissemination on the screen is still vivid credibility, other media are unparalleled in the sports information conveyed in today's society have an enormous advantage. The spread of television on sports, but also images, sound and live commentary and television subtitles three media to express through the TV screen to the audience with a strong sense of the scene, vivid and intuitive, and interactive and more appealing. Artistic gymnastics, synchronized swimming melodic beauty, physical beauty, swimming, track and field intense, suspense, not let the audience intoxicated. Some deep digging more sports programs to meet different levels of knowledge and interest in the audience, sporting spirit, ethos, skills competitions and so have been fully explained. TV sports media so that people can get both in the family knowledge horizons, enjoy the wonderful sports programs, but also to learn effective ways to exercise, enhance physical fitness, sports and cultural enrich people's lives [1].

Data shows that network television is more frequent contact with the Chinese mass media. In recent years, the network has been popular in the country, breaking the television transmission limitations in the area, greatly expanding the television sports media space. Compared TV Sports Media, the sports media network features in its timely, comprehensive, multi-angle cut, and have some interaction, and sports enthusiasts can communicate in different places. And due to the limitations of the prior art, is still very limited network bandwidth for video transmission clarity and speed is also far less than TV networks.

Sports information in a comprehensive amount of information the newspaper reported the proportion of the total amount can guarantee about 1/4, with the rapid development of China's journalism major newspapers in order to meet the demand for information have been expanded edition growth, most cities the newspapers have opened up a special edition sports or weekly. Newspaper columns of sports coverage, covering most sports fans the focus of attention, and can be viewed anytime, anywhere, is the most important addition to television and Internet sports media. 


\section{The Concept of Lifelong Physical}

Lifelong physical, refers to a person lifelong physical exercise and receive physical education instruction and education. Lifelong implications of sports, including two aspects: First, the people from the beginning of life until the end of life, learning and participating in physical exercise activities, so there is a clear purpose for life, so that life is always a lifetime sport become indispensable content ; Second, under the guidance of lifelong PE thought to systematic sports overall as the goal, people at different times and in different areas of life to participate in sports activities provide practice opportunities.

Lifetime Sports is based on the variation of human development, the role of physical exercise, as well as the development of modern society requires people constantly raised, accompanied by the development of lifelong education and developed. Human activities must adhere to the law requires physical exercise regularly, if not consistently, it cannot produce sustained effect of exercise. Modern lifestyle requires physical exercise to become an integral part of people's daily lives, become an important part of modern life [2]. Based on lifelong physical point of view, human life will continue to sport, it is the whole process of pre-school education sports, school sports and community sports and other physical education levels constitute lifelong sport.

Lifetime Sports is a new concept of education, social development, in order to meet the demand for talent produced and developed in the development of increasingly shows its inherent basic features. The first is universal, from Table 1, the lifelong physical objects are of all ages, for all members of society, including infants, children, adolescents and the elderly, etc.; followed by lifelong, is a person from birth to the death of a continuous process of physical education; Third, science, physical education system, principles and policies, institutional and other measures should be conducive to the establishment of a network dimensional education system, should help to promote pre-school sports, family sports, school integration of sports, social sports, so that members of the full and harmonious development of society in moral, intellectual, physical, and aesthetic aspects; Fourth, democracy, lifelong sports should be under the unified leadership of the state, all localities and departments to participate in sports management activities, socialize sport [3].

Table 1 The contents of lifelong education

\begin{tabular}{|c|c|c|c|c|}
\hline Age & Teaching Affairs & Teaching Target & $\begin{array}{c}\text { Teaching } \\
\text { Environment }\end{array}$ & Knowledge Range \\
\hline Before born & Embryo & Parents & Parent body & Genetics \\
\hline $0 \sim 2$ & Breed & Parents, baby & Home, Baby room & Child care \\
\hline $2 \sim 6$ & Upgrowth & Parents, ,baby & Home, Kindergarten & Child care \\
\hline $6 \sim 12$ & Upgrowth & Parents, Student & $\begin{array}{c}\text { Home, Primary } \\
\text { school }\end{array}$ & $\begin{array}{c}\text { Kindergarten } \\
\text { knowledge }\end{array}$ \\
\hline $12 \sim 17$ & Upgrowth & Teacher, Student & $\begin{array}{c}\text { Home, Middle } \\
\text { school }\end{array}$ & $\begin{array}{c}\text { middle school } \\
\text { knowledge }\end{array}$ \\
\hline $17 \sim 22$ & Upgrowth & Teacher, Student & University, Society & University knowledge \\
\hline $22 \sim 50$ & Upgrowth & Worker & Society, Family & Fiteness knowledge \\
\hline After 50 & conserve & Worker, the aged & Society, Family & Conserve knowledge \\
\hline
\end{tabular}

\section{The Formation of Public Sport Awareness}

Sports consciousness is that people's basic views held by sports, is that people in the sports environment, motivation, purpose, needs and comprehensive reflection of emotional consciousness, which permeates all areas of sports performance sports people in fitness, recreational, aesthetic and psychological, moral, intellectual and other aspects of the degree of embodied cognition. From a scientific point of view, a person's sense of orientation determines their behavior motivation, and motivation determines a person's behavioral goals and aspirations. Sports games have its unique charm, making a positive public awareness of sport to inspire the desire to participate in sports.

Sports information obtained from the media and people have great relevance sports 
consciousness, the media spread the awareness of sport to promote cultural understanding and love of sports, making people more in contact sports and in-depth understanding of its rules. On the one hand, the sports media for sports activities provide a wide audience, so that sports better perform its social function, but also for the economic development of sports provides a valuable platform. On the other hand, sports media allow more people to participate in sports activities in the body to provide a steady stream of reinforcements for the development of sport. Modern Communication Studies prove: Sports media in the dissemination of information and scientific and cultural knowledge, has unique advantages, it can also affect people ideologies subtly change people's behavior, in particular the impact on the general public especially [4]. It can not only stimulate public interest in sports and in helping them to try to have some effect on the exercise, they can influence the formation and development of the concept of sports consciousness.

\section{Active Role in Sports Consciousness Played by the Mass Sports Media}

Influence of sports media gradually increased aid, bringing a corresponding change to human life, thoughts and ideas. In order to meet the economic and competitive media needs to maximize sports has been irritating, dramatic and entertaining, entertaining way to attract the attention of sports dynamic, happy and healthy participation in various sports, get relaxed body and spiritual double enjoyment.

Sports media can promote public understanding of sports to enhance their attention to sports activities and sports hobbies and interests, to lay a solid foundation for lifelong physical goals. The more contact sports media students to actively participate in sports activities, the higher, the more fully the role and significance of sports knowledge, the more they contribute to the formation of proper sporting values.

Sporting event as a public focus, through objective, true, accurate and timely reports, let the public know of sports development in all aspects of the operation, and by public opinion purification sporting environment, to some extent, subtly enhanced public awareness of fair and equitable ; sports star is the incarnation of a national hero, is the embodiment of human beings skill and wisdom, and the public has an important educational role, they demonstrate the guiding role of the public has become a cultural trend, good for promoting public awareness and national competition pride; Olympic movement higher, faster, stronger motto fully aired sports progressive, insatiable spirit of struggle. These effects also make the public better and more effective participation in sports activities go, and to carry forward the spirit of sport on the road of life.

\section{The Improvement Required by Sports Media}

Current situation of sports media, and by the history of today's social and economic situation of China's sports undertakings comprehensive decision, with considerable complexity, though has made significant achievements, but in the dissemination of sports consciousness, there are still some deficiencies.

For a long time, due to the state-run sports has a strong purpose, the sports center in the country to support sports, ignoring the essence of sport's popularity led to our competitive power, the strange phenomenon of sports weaker countries. This trend has also affected the sports media, pushing Chongjin Biao doctrine, ignoring the spirit of sports and educational values, uncommon for mass sports or school sports coverage or topics. With the steady progress in building a moderately prosperous society, we need to change this anomaly as soon as possible, the development of public health into our sport sports construction plans. Sports Media should be appropriate reforms and adjustments, the importance of mass sports coverage, promote mass sports development [5].

With the changes in the economic development and social structure increasingly wide audience of sports coverage, more and more involved in the content. Sports Media should broaden the scope of coverage to meet the needs of social development, while the reduction of the social function of sport has a greater role in promoting. For public groups, on one hand, the content should focus on sports information literacy development of their sport, that content is not limited to the surface 
spread of entertainment content, to focus on sports knowledge, health, fitness and other aspects of indoctrination, otherwise, it will the formation of the sports information if the palm, and sports literacy is relatively high on paper is not the case. On the other hand, the sports media should be the sport itself as a medium, the use of public concern, dig sports activities sublime spiritual refracted, reflected the social attributes of sport, namely in the Beijing Olympic Games to promote the humanities. CCTV is currently reported on a variety of large-scale sporting events, there is always such a special program from the stage to behind the scenes, the scene from the lower court, from athletes to coaches, sparring, from game to life, to give the public a large sports concept, far-reaching.

Sports Media has now matured in terms of its impact on the general public and we should pay more attention to its content and coverage reports, to guide the public to form a positive attitude and sporting behavior sports, develop good exercise habits, proper sports consciousness create an environment conducive to the growth of public health.

\section{Conclusions}

Through the mass media sports knowledge, sports, sports and entertainment, the public media enable the public to increase the understanding of sports, raise awareness and develop interest in sports-loving. All of those lay a solid foundation for the lifelong physical consciousness. Through this study, we find that the more mass media usually contact sports information people to participate in sports activities higher enthusiasm for the role and significance of sport is also more fully understanding, which helps them to form the correct values of sport, lifelong sports consciousness.

\section{References}

[1] Hu Zhengrong: Journal of Physical Education, Vo1.22 (2008) No.5, p.62-67.

[2] Wang Huilin: Journal of Shanghai sports institute, Vo1.1 (2011) No.3, p.71-78.

[3] Chen Tianren: Fujian Sports Science and Technology, Vo1.9 (2010) No.7, p.82-86.

[4] Zhou Xiaodong Journal of Southeast University, Vo1.12 (2001) No.7, p.101-114.

[5] He Jia, Zhou Fangmao: Journal of Beijing Sport University, Vo1.2 (2012) No.2, p. 36-42. 